\title{
A discussion of individual variability, in activity- based interventions, using the niche concept
}

- S. Dada, ${ }^{* *}$ Centre for Augmentative and Alternative Communication, Communication Pathology Building, Main Campus, University of Pretoria, Pretoria, Gauteng, South Africa

- M. Granlund†¥†Department of Social Sciences, Västerås, Sweden, and‡ALA Research Foundation, associated with the Association for Persons with Intellectual Disability in Sweden, Stockholm, Sweden and

- E. Alant**Centre for Augmentative and Alternative Communication, Communication Pathology Building, Main Campus, University of Pretoria, Pretoria, Gauteng, South AfricaErna Alant, Centre for Augmentative and Alternative Communication, Communication Pathology Building, Main Campus, University of Pretoria, Pretoria, Gauteng 0002, South Africa E-mail: erna.alant@up.ac.za

*Centre for Augmentative and Alternative Communication, Communication Pathology Building, Main Campus, University of Pretoria, Pretoria, Gauteng, South Africa †Department of Social Sciences, Västerås, Sweden, and $\ddagger A L A$ Research Foundation, associated with the Association for Persons with Intellectual Disability in Sweden, Stockholm, Sweden

\section{Abstract}

Background Activity-based intervention has been defined as a child-directed, transactional approach that uses logically occurring antecedents and consequences to develop functional and generative skills by embedding intervention of children's individual goals and objectives in routine, planned or child-initiated activities. In this approach, clear goals and objectives that are functional and embedded in a play activities or routines are developed. The teacher mediates the child's environment to facilitate learning with the child directing the teacher on the pace, duration spent on the objective. Learning and development in this framework occur through both a carefully planned environment and adult facilitation. Progress made by a child using this approach focuses on observational data that describe if the child is able to respond in functional and generative ways. While activity-based interventions are usually provided for a group of children, progress is measured by describing individual children's responses. Individual variations in the children's progress, despite exposure to the same interventions are an area that is seldom discussed. This article aims to explore the niche concept and its application to explaining this variation between individuals. 


\section{Methods}

Four children participated in this single-subject, multiple-probe study across four participants. A 3-week long activity-based aided language stimulation programme was developed. The effect of the programme was determined by describing the individual participants understanding of the 24 targeted vocabulary items.

Results The results of the activity-based language programme are presented and the variability among the participants is discussed using the niche concept. The role of the niche concept in individual development is described and the implications thereof are discussed.

Conclusions Finally, activity-based intervention research is placed in a systems perspective and possible outcome measures of this intervention are discussed from a multidimensional ecological perspective.

\section{Introduction}

Intervention is defined as 'a super-ordinate concept for the different intentional steps taken to change persons, interaction, events or environment in a desired direction' (Granlund \& Björck-Åkesson 2005, p. 277). Language interventions can be characterized by a continuum running from highly structured didactic teaching to naturalistic child-orientated intervention like activity-based interventions (Fey 1986; Beukelman \& Mirenda 1992). Few of these intervention approaches have been evaluated with a focus on within-group variability. A similar trend is evident in other areas of contemporary intervention research, e.g. psychotherapy research (Westen et al. 2004) and early intervention (Guralnick 1997) where the problem of withingroup variability is intensely discussed. Clients receiving the same treatment respond differently and clients who receive different treatments have identical outcomes. The aim of this paper is to discuss within-group variability among participants in an activity-based aided language stimulation programme. The niche concept is discussed and applied in order to facilitate the understanding of within-group variability. A niche refers to the unique way in which and individual self-selects into certain groups or contexts that matches their individual characteristics (Wachs 2000). As Super and Harkness (1986) point out, this would encompass the physical and social setting of the child, customs that drive child rearing and parental beliefs and goals. More contemporary definitions (used in this article), however, also consider the niche to encompass the physical context with emphasis on the individual as well as their interpersonal characteristics within that setting.

\section{Activity-based intervention}

Activity-based intervention, a naturalistic approach, has gained widespread appeal and support as an approach for instruction with children with and without disabilities (Pretti-Frontzcak et al. 2003). It has been widely used in early childhood intervention programmes (Losardo \& Bricker 1994; Hepting \& Goldstein 1996; Hemmeter \& Grisham-Brown 1997; Bricker et al. 1998; Rule et al. 1998). Activity-based intervention is a comprehensive approach to assessment, intervention and evaluation 
offering a framework for the use of developmentally appropriate practices with young children with special needs that attempts to incorporate the very best of early childhood with regular early childhood education (Bricker \& Cripe 1992, p. 31). It is a focused intervention that is activity-centred and embeds training in child-initiated, motivating, planned or routine activities. The approach emphasizes meaningful, functional and developmentally appropriate activities that recognize the interaction between the child and environment. It is a combination of selected strategies found in early childhood and behaviour analytic approaches.

Activity-based intervention draws on the work of Piaget, Dewey and Vygotsky (Bricker \& Cripe 1992) and based on these three theories the approach emphasizes that learning should not be separated from the context in which it occurs. It also emphasizes that learning should occur in activities that reflect the demands of the daily life environment, thereby arguing that the approach greatly assists children in developing and generalizing responses. The role of the interventionist is to arrange the environment to capitalize on the child's motivation to explore, initiate and master the environment.

Activity-based intervention has been the subject of much research (Bricker \& Sheehan 1981; Bailey \& Bricker 1985; Bricker \& Gumerlock 1988; Giumento 1990; Pretti-Frontzcak \& Bricker 2001). The results generally indicate that with activitybased intervention, children acquire skills rapidly and also generalize skills to other contexts and domains. Studies that have evaluated activity-based intervention have primarily focused on its effectiveness as a comprehensive approach and have not targeted its individual intervention strategies namely, following children's initiations, targeting meaningful goals (Losardo \& Bricker 1994; Hemmeter \& Grisham-Brown 1997; Bricker et al. 1998). Second-generation research that examines specific intervention strategies is needed (Guralnick 1997) and have been initiated in a study that attempted to focus specifically on the embedding strategy, a procedure that gives children the opportunity to practice goals within a meaningful activity (PrettiFrontzcak \& Bricker 2001). Their findings revealed that the teachers tended to use the embedding strategy in a limited way mostly in one-on-one situations with the child and in language and pre-academic activities therefore not capitalizing on using group activities. This highlights the need for training to be conceptualized within activities that are functional and meaningful and that the principles of activity-based interventions are met.

Single-subject designs and group designs have been used to demonstrate the effectiveness of interventions by comparing group averages between experimental groups and control groups. Little emphasis is given to within-group or betweenactivities variability evidenced by standard deviations and pattern variability. It may be that different children do not interact with the environment in the same manner in identical activity settings and that an activity-based intervention needs to be individualized to optimize the effect of the intervention. The focus of the intervention studies discussed above highlight that research in the area of activity-based interventions has focused on investigating the effectiveness of the approach broadly. There is, however, a need to clarify, define and focus research on specific elements of the approach and to also consider the effect on different domains including language, speech and motor development. 


\section{Niches}

One way in which individual and environmental characteristics can influence variability is the availability of niches within an environment. Usually a person or child does not interact with all aspects of the environment (Wachs 2000). The part of the environment in which the person in a specific activity interacts relatively continuously with physical and social aspects of the immediate setting (Wachs 2000) is described as the niche. The niche concept is based on the hypothesis that individuals self-select into certain groups or contexts that match their own individual characteristics (Wachs 2000, p. 117). However, this does not imply that all niches are equally available to an individual and that the individual simply needs to self-select one that best suites one. He states that individual characteristics may act to close or increase the availability of niches. Niches can be closed to an individual as a function of societal constraints and perceptions about the openness of a setting. For example, Wachs (2000) stated that factors such as age and large parental networks opens niches as it allows for the child to increase their experiences as well as extend their own peer networks. On the other hand, niches can be closed by the following factors; societally non-approved behaviours including aggression, cognitive deficits, dependency, learned helplessness, malnutrition, contextual instability (family moves), low parental socio-economic status, low education level, or family poverty and finally discrimination. For example the participants in this study experienced societal segregation as participants attended a school for children with disabilities. Niches occur in larger socio-cultural contexts and these can moderate the effect on individual niches. Niche change is a gradual and slow process that usually occurs when there are changes in higher order (cultural) rather than individual influences (Wachs 2000).

Individuals select niches that are similar to their talents, goals and expectations thereby selecting homogenous niches, which, could act to reinforce and maintain selfexpectations and goals causing stabilization of patterns. On the other hand, individuals that select more heterogeneous niches requiring the individual to adapt and adjust accordingly would more likely produce an individual that is more flexible and have a wide variety of behavioural strategies. Some individuals with characteristics that are not valued in their society may not have the freedom to select their own niches and are thus restricted in their niches. This restriction is likely to restrict the individual's ability to change even when change is possible as they have had less exposure to alternative ways of behaviour and thinking (Wachs 2000). The niche concept assists in understanding individual variations that occur in individuals and may account for variations seen in the data, that will be discussed later in this paper, and highlights the possibility that with in an activity-based intervention children could have different niches with in the same activity. While it is difficult to obtain data on niches, it is important to consider the concepts and the potential impact it has on development in individuals.

\section{Methods}

In a single-subject, multiple-probe study using activity-based interventions for children with disabilities (Dada 2004; Dada \& Alant, submitted) considerable withingroup variability among the four participants was found. The aim of the study was to determine the impact of a 3-week long aided language stimulation programme on the 
receptive language skills of children with little or no functional speech. Aided language stimulation refers to a technique in which a facilitator or communication partner simultaneously points to picture symbols on a board in conjunction with providing ongoing spoken language stimulation (Goossens' 1989). There is also an emphasis on providing intervention in an activity-based format within the child's natural contexts or routines Goossens' (1989). The aided language stimulation programme was embedded in three daily activities viz. arts and crafts, food preparation and story time activity. Each activity was targeted for 1 week and repeated daily over the duration of five subsequent days. Eight target receptive vocabulary items were taught within each activity. Thereafter, a second activity was introduced. The acquisitions of all 24-target items were probed throughout the duration of the 3-week intervention period. The same probes on all 24 items were conducted on days 1,3 and 5 of each week for the duration of the intervention. The aided language stimulation was provided in a group format so that all four participants received exactly the same intervention.

Four children participated in this study. The children were between the ages of 8.112.1 years and had little or no functional speech. There were three female (participants B, C, D) and one male participant (participant A). Three participants were diagnosed as having cerebral palsy (participants A, B, C) and one Downs syndrome (participant $\mathrm{D}$ ). They had no hearing impairments and were able to identify line drawings. There were variations in their expressive and receptive language abilities. Table 1 provides a more detailed description of the participants.

\section{Results}

Table 2 describes the performance of each of the participants during the baseline and probe measures for all three activities. The total number of correct responses for each participant is presented in the table. The maximum number of correct responses that each participant could obtain is eight. The results indicated that all the participants acquired the target receptive vocabulary items. There were, however, variations in terms of the rate of acquisition as is evident in Table 2 as well as in the vocabulary items acquired as illustrated in Table 3.

It is evident from Table 2 that there is variability in the performance of the participants. Generally, the participants obtained a stable baseline across activities however; both the rate and the acquisition of specific target vocabulary items vary across the participants. For the arts and crafts activity, the participants acquired some of the target items during week 1 , the intervention phase. However, their performance improved even when the implementation of the arts and crafts activity had ceased. It is evident that there is variability across the participants with the number of correct responses obtained after the first intervention week and then in the subsequent probe sessions. Participants A and D acquire the target vocabulary items at a slower pace for the first two probes on week 1 days 1 and 3, respectively. However, after the final intervention period they acquire the targets and retain them in the remaining probes in weeks 2 and 3. Participants B and C, however, start acquiring the target vocabulary items as early as week 1 days 1 and 3 . The participants' performance on the food preparation activity was fairly consistent across participants with all participants starting to acquire the items during week 2 day 3 with similar patterns of acquisition in week 3. During the final probe the participants obtained either $7 / 8$ or $8 / 8$, indicating 
that each participant acquired the target items for the food preparation activity. A similar trend occurs for the story time activity. The participants obtained a stable baseline (except participant B) until the implementation of the activity in week 3 . During the final probe they obtained scores of between $5 / 8$ and $7 / 8$. This indicates the acquisition of the target vocabulary items after the introduction of the activity. However, it should be noted that all the target items for the story time activity were not acquired during the intervention period. It is possible that the items were not acquired, as the trend of the other activities is that the maximum score was usually achieved in following the intervention period after the final exposure to the aided language stimulation programme. While there is some variability in the rate of acquisition of the target vocabulary items, there is also variability with the actual vocabulary items that were acquired as illustrated in Table 3.

Table 3 illustrates the acquisition of each vocabulary item for the four participants during each probe illustrating the frequency with which the targets were acquired. The target items were correctly responded too by all four participants in the final probe except for the items less, same, different, empty, pink, soft, hard and three. There are various possible explanations for the reasons why these items were not acquired. These could be related to the complexity of the concept, the cognitive abilities of the participants as well as the possibility of the concepts having low iconicity (i.e. poor visual relationship between the concept and the graphic symbol).

\section{Discussion}

Of interest are the possible explanations for the variations in the participation acquisition of the vocabulary items. A factor commonly discussed in the literature is that of the participants' speech comprehension skills (Sevcik \& Romski 1986; Romski \& Sevcik 1993; Franklin et al. 1996; Carr et al. 2000; Rowland \& Schweigert 2000). The participants performed differently on the receptive language assessments conducted prior to the implementation of the aided language stimulation programme as is evident in Table 1. All the participants performed poorer on the assessments with the performance 3.5-4 years. However, participants B and D obtained better scores on the receptive vocabulary measures than the other two participants. Participants A and $\mathrm{B}$ performed better on the general receptive language measures. It would appear that the participants $\mathrm{A}$ and $\mathrm{B}$ had better general speech comprehension abilities and were therefore able to cope better with the task at hand of mapping novel words that they were exposed to during the session. Another important consideration is the environment of the participants. The participants did not receive any augmentative and alternative communication intervention prior to the implementation of the aided language stimulation despite them being candidates for such an intervention. It could be assumed that partly the environment (home and school) did not model augmentative communication intervention (or perhaps have the necessary skills to implement it). This could have resulted in a restriction of the participants' niches. The participants described in this activity-based intervention had little or no functional speech, which Calculator (1997) believes results in early language experiences that comprise reduced amounts of linguistic input. It would appear that the language input provided to children with little or no functional speech, while incomplete, is also qualitatively different from that given to typically developing children (Blockberger \& Sutton 2003). The qualitative differences include more directive interaction, more questioning and fewer opportunities for initiations. This pattern is evident even 
though responsive rather than directive patterns of interaction have been found to facilitate language development (Hanzlik 1990; Girolametto et al. 1999). It could be argued that these differences in language input could close niches for the participants in this study. Participants A, B and C stayed at the school premises and only visited their home environments during vacations while participant $\mathrm{D}$ visited home daily. It could be postulated that the language input that participant $\mathrm{D}$ received after school was qualitatively different from the other participants' experiences. Other intrinsic or personal factors discussed in the literature refer to motivation (Rowland \& Schweigert 2000), individual learning styles (Iacono 1992), cognitive processing (Light \& Lindsay 1991) and concept of engagement, which refers to the quantity if time spent interacting with the environment in a way that is contextually, and developmentally appropriate (McWilliam \& Bailey 1995). Most of these factors are focused at the individual level and instructional level. What is needed, however, is a closer examination of the specific interactions between these aspects for individuals. Wachs (1996) points out that there are multiple influences on development and that many of these influences covary with each other. In addition, he describes the concept of equifinality, which refers to identical outcomes being achieved thorough different pathways, and multifinality describes different outcomes reached through the same pathway. These concepts would explain the variations in the participants' performance in the study. While the intervention provided to the participants were the same participants characteristics varied and the outcomes for each participant differed in terms of the number of target vocabulary items acquired.

\section{Implications of niche concept}

Both the availability of the environment as well as the person's perceived availability of niches influences participation in life situations (Almqvist \& Granlund 2005). Niche organizational structure can either stimulate or inhibit participation in life situations and a disability tends to affect organizational aspects of the niches in a manner that closes niches (Wachs 2000). It has been hypothesized that perhaps children with disabilities, because of both personal characteristics and the organizational aspects of their niches, tend to over time develop niches that would decrease the probability of positive and strong patterns in their perceived availability of niches, autonomy, locus of control and interaction with others (Eriksson \& Granlund 2004). It would therefore be relevant to create opportunities for children with disabilities to have the opportunities to be both active and interacting with their environment.

Activity-based interventions, provides a natural context for interventions and is implemented within the context of daily activities. These daily activities of children with disabilities tend to differ and are more limited than those of typically developing peers. Studies reveal that children with disabilities tend be excluded from activities (Prellwitz et al. 2001), spend more time in solitary play (Guralnick \& Groom 1987; Howard 1996) more time with adults and have more restricted peer relations (Skär \& Tamm 2002). In addition, it should be noted that even with exposure to similar activities, each individual has different niches within the activity. It would therefore be important that the activity-based interventions also aim to increase the number and type of daily activities of these children and could be used as a vehicle for expanding the children's exposure to different interactions within different settings. It would also be relevant to ensure that the involvement in the activity is active and that it facilitates 
participation, which as discussed above, is more than merely doing or being involved in an activity but would also require consideration of the child's niche potential within the activity.

\section{Conclusion and recommendations for future research}

Activity-based intervention as discussed above has merits as a naturalistic approach to intervention. Its advantages to facilitating learning and retention have been highlighted. However, it is also evident that the research in this area is fairly limited both in the number of studies as well as the nature of these studies in terms of the outcomes that are measured. This paper proposes an approach to activity-based intervention that focuses on the idea that it is possible that contextual niches exist within activities which may account for individual variability among participants and may also provide insights in to the possibilities for using activity-based instructions to develop these niches.

Research on niches, by describing and examining participants' niches, could provide explanations of individual variability in performances and provide an alternative research agenda to the commonly used strategy of controlling participants through stringent participation selection criteria. This would require a new line of inquiry focused on descriptive criteria that can enhance understanding of different ways in which individuals relate to similar activities and situations. This paper raised the issue of the role of niches in explaining individual variability within a specific training context, future research needs to explore further how specific aspects relating to the concept of niches can enhance understanding of individual variability.

\section{References}

Almqvist, L. \& Granlund, M. (2005) Participation in school environment of children and youth with disabilities. Scandinavian Journal of Psychology, 46, 305-314.

Bailey, E. \& Bricker, D. (1985) Evaluation of a three year early intervention demonstrations project. Topics in Early Childhood Special Education, 5, 52-56.

Beukelman, D. R. \& Mirenda, P. (1992) Augmentative and Alternative Communication: Management of Severe Communication Disorders in Children and Adults, 3rd edn. Paul H. Brookes Publishing, Baltimore, MD, USA.

Blockberger, S. \& Sutton, A. (2003) Toward linguistic competence: language experiences and knowledge of children with extremely limited speech. In: Communicative Competence for Individuals Who Use AAC from Research to Effective Practice (eds J. C. Light, D. R. Beukelman \& J. Reichle), pp. 63-106. Paul H. Brookes Publishing, Baltimore, MD, USA.

Bricker, D. \& Cripe, J. J. W. (1992) An Activity Based Approach to Early Intervention. Paul H. Brookes Publishing, Baltimore, MD, USA. 
Bricker, D. \& Gumerlock, S. (1988) Application of a three level evaluation plan for monitoring child progress and program effects. Journal of Special Education, 22, 6681.

Bricker, D. \& Sheehan, R. (1981) Effectiveness of an early intervention program as indexed by child change. Journal of the Division for Early Childhood, 4, 11-27.

Bricker, D. D., Pretti-Frontzcak, K. L. \& McComas, N. R. (1998) An Activity Based Approach to Early Intervention, 2nd edn. Paul H. Brookes Publishing, Baltimore, MD, USA.

Calculator, S. N. (1997) Fostering early language acquisition and AAC use: exploring reciprocal influences between children and their environments. Augmentative and Alternative Communication, 13, 149-157.

Carr, D., Wilkinson, K. M., Blackman, D. \& McIlvane, W. J. (2000) Equivalence classes on individuals with limited verbal repertoire. Journal of Experimental Analysis of Behavior, 74, 101-114.

Dada, S. (2004) The impact of aided language stimulation on the receptive language abilities of children with little or no functional speech. Unpublished Doctoral Dissertation, University of Pretoria, Pretoria, South Africa.

Eriksson, L. \& Granlund, M. (2004) Conceptions of participation in students with disabilities and persons in their close environment. Journal of Developmental and Physical Disabilities, 16, 229-245.

Fey, M. (1986) Language Intervention with Young Children. College Hill Press, San Diego, CA, USA.

Franklin, K., Mirenda, P. \& Phillips, G. (1996) Comparison of five symbol assessment protocols with non-disabled preschoolers and learners with severe cognitive intellectual disabilities. Augmentative and Alternative Communication, 12, 63-77.

Girolametto, L., Weitzman, E., Wiigs, M. \& Pearce, P. (1999) The relationship between two maternal language measures and language development on toddlers with expressive vocabulary delays. American Journal of Speech-Language Pathology, 8, 364-374.

Giumento, A. (1990) The effectiveness of two intervention procedures on the acquisition and generalization of object labels by young children who are at risk or who have developmental delays. Unpublished Doctoral Thesis, University of Oregon, OR, USA.

Goossens', C. (1989) Aided communication intervention before assessment: a case study of her child with cerebral palsy. Augmentative and Alternative Communication, $5,14-26$. 
Granlund, M. \& Björck-Åkesson, E. (2005) Participation and general competence do type and degree of disability really matter? In: Change, Resistance and Reflection: Current Nordic Disability Research (eds R. Traustadottir, A. Gustavsson, J. Tøssebro \& J. T. Sandvin), pp. 277-294. Studentlitteratur, Lund, Sweden.

Guralnick, M. (ed.) (1997) The Effectiveness of Early Intervention. Paul H. Brookes Publishing, Baltimore, MD, USA.

Guralnick, M. \& Groom, J. M. (1987) Dyadic peer interaction of mildly delayed and non handicapped preschool children. American Journal of Mental Deficiency, 10, $140-150$.

Hanzlik, J. (1990) Nonverbal interaction patterns of mothers and their infants with cerebral palsy. Education and Training in Mental Retardation, 25, 333-343.

Hemmeter, M. L. \& Grisham-Brown, J. L. (1997) Developing children’s language in inclusive early childhood classrooms. Dimensions of Early Educations, 25, 6-13.

Hepting, N. \& Goldstein, H. (1996) What's natural about naturalistic language intervention? Journal of Early Intervention, 20, 250-264.

Howard, L. (1996) A comparison of leisure-time activities between able-bodied children and children with physical disabilities. British Journal of Occupational Therapy, 12, 570-574.

Iacono, T. (1992) Individual learning styles and augmentative and alternative communication. Augmentative and Alternative Communication, 8, 33-40.

Light, J. \& Lindsay, P. (1991) Cognitive science and augmentative and alternative communication. Augmentative and Alternative Communication, 7, 186-203.

Losardo, A. \& Bricker, D. D. (1994) An activity based intervention and direct instruction: a comparison study. American Journal of Mental Retardation, 98, 744765.

McWilliam, R. A. \& Bailey, D. B. (1995) Effects of classroom social structure and disability on engagement. Topics in Early Childhood Special Education, 15, 123-148.

Prellwitz, M., Tamm, M. \& Lindqvist, R. (2001) Are playgrounds in Norrland (northern Sweden) accessible to children with restricted mobility? Scandinavian Journal of Disability Research, 16, 917-931.

Pretti-Frontzcak, K. L. \& Bricker, D. D. (2001) Use of the embedding strategy by early childhood education and early childhood special education teachers. Infant and Toddler Intervention: The Transdisciplinary Journal, 11, 111-128.

Pretti-Frontzcak, K. L., Barr, D. M. \& Carter, M. M. A. (2003) Research and resources related to activity based intervention, embedded learning opportunities and routines-based instructions: an annotated bibliography. Topics in Early Childhood Special Education, 23, 29-39. 
Romski, M. A. \& Sevcik, R. A. (1993) Language comprehension: considerations for augmentative and alternative communication. Augmentative and Alternative Communication, 9, 281-285.

Rowland, C. \& Schweigert, P. (2000) Tangible symbols, tangible outcomes. Augmentative and Alternative Communication, 16, 61-205.

Rule, S., Losardo, A., Dinnebeil, L., Kaiser, A. \& Rowland, C. (1998) Translating research on naturalistic instruction in to practice. Journal of Early Intervention, 21, 283-293.

Sevcik, R. \& Romski, M. A. (1986) Representational matching skills of persons with severe retardation. Augmentative and Alternative Communication, 2, 160-164.

Skär, L. \& Tamm, M. (2002) Disability and social network. A comparison between children and adolescents with and without disabilities. Scandinavian Journal of Disability and Research, 4, 118-137.

Super, C. \& Harkness, S. (1986) The developmental niche. International Journal of Behavioral Development, 9, 545-569.

Wachs, T. D. (1996) Known and potential processes underlying developmental trajectories in childhood and adolescence. American Psychological Association, 32, 796-801.

Wachs, T. D. (2000) Necessary but not Sufficient- the Respective Roles of Single and Multiple Influences on Individual Development. American Psychological Association, Washington, DC, USA.

Westen, D., Novotny, C. M. \& Thompson-Brenner, H. (2004) The empirical status of empirically supported psychotherapies: assumptions, findings, and reporting in controlled clinical trials. Psychological Bulletin, 130, 631-663. 
Table 1. Description of the participants

\begin{tabular}{|c|c|c|c|c|}
\hline \multirow{2}{*}{ Criteria } & \multicolumn{4}{|c|}{ Participants } \\
\hline & Participant A & Participant B & Participant C & Participant D \\
\hline Age (years) & 8.5 & 10.1 & 8.1 & 12.1 \\
\hline Gender & Male & Female & Female & Female \\
\hline Diagnosis & Cerebral palsy & Cerebral palsy & Cerebral palsy & Down syndrome \\
\hline Grade & Junior class A & Junior class A & Junior class A & Junior class B \\
\hline Boarding school & Stayed on school days & Stayed on school days & Stayed on school days & Did not stay at boarding school \\
\hline $\begin{array}{l}\text { Attending school } \\
\text { (years) }\end{array}$ & 4 & 5 & 4 & 5 \\
\hline Home language & Zulu & Sepedi & Sepedi & Sepedi \\
\hline Physical status & $\begin{array}{l}\text { Right hemiplegia with } \\
\text { greater involvement of } \\
\text { the lower extremities. } \\
\text { Able to direct select. }\end{array}$ & $\begin{array}{l}\text { Right hemiplegia with more involvement } \\
\text { of the upper extremities Able to direct } \\
\text { select. }\end{array}$ & $\begin{array}{l}\text { Right hemiplegia with more } \\
\text { involvement of the upper } \\
\text { extremities. Able to direct } \\
\text { select. }\end{array}$ & $\begin{array}{l}\text { Physically able bodied, except for } \\
\text { difficulties with gross and fine motor } \\
\text { skills during some functional activities } \\
\text { reported by the occupational therapist. } \\
\text { Able to direct select. }\end{array}$ \\
\hline $\begin{array}{l}\text { Activities of daily } \\
\text { living }\end{array}$ & $\begin{array}{l}\text { Independent in terms } \\
\text { of eating, dressing and } \\
\text { walking. }\end{array}$ & $\begin{array}{l}\text { Independent in terms of eating, dressing } \\
\text { and walking. }\end{array}$ & $\begin{array}{l}\text { Independent in terms of } \\
\text { eating and walking. } \\
\text { Required some assistance } \\
\text { with fine motor skills for } \\
\text { dressing. }\end{array}$ & $\begin{array}{l}\text { Independent in terms of eating, } \\
\text { dressing and walking. }\end{array}$ \\
\hline Communication & $\begin{array}{l}\text { Used vocalizations, } \\
\text { natural gestures and } \\
\text { speech. }\end{array}$ & $\begin{array}{l}\text { Used vocalizations, natural gestures and } \\
\text { speech. }\end{array}$ & $\begin{array}{l}\text { Used vocalizations, natural } \\
\text { gestures and speech. }\end{array}$ & $\begin{array}{l}\text { Used vocalizations, natural gestures } \\
\text { and speech. }\end{array}$ \\
\hline Speech characteristics & $\begin{array}{l}\text { His speech was } \\
\text { intelligible to familiar } \\
\text { partners and less so to } \\
\text { unfamiliar partners. } \\
\text { His speech included } \\
\text { substitutions and } \\
\text { omissions. }\end{array}$ & $\begin{array}{l}\text { Her speech had frequent misarticulations, } \\
\text { and was characterized by substitutions and } \\
\text { omissions. She had difficulty with lip } \\
\text { closure and was unable to produce } \\
\text { bilabials resulting in speech with a vowel- } \\
\text { like quality }\end{array}$ & $\begin{array}{l}\text { Her speech was unintelligible } \\
\text { to both familiar and } \\
\text { unfamiliar partners. Her } \\
\text { misarticulations comprised } \\
\text { primarily omissions. }\end{array}$ & $\begin{array}{l}\text { Her speech was intelligible to familiar } \\
\text { partners and less so to unfamiliar } \\
\text { partners. } \\
\text { Her speech included substitutions and } \\
\text { omissions. Her tongue mobility was } \\
\text { compromised, which resulted in a } \\
\text { tongue thrust with the associated } \\
\text { impact on her speech intelligibility and } \\
\text { characteristics. }\end{array}$ \\
\hline
\end{tabular}




\begin{tabular}{|l|l|l|l|l|}
\hline \multicolumn{1}{|c|}{ Criteria } & \multicolumn{3}{|c|}{ Participants } \\
\cline { 2 - 5 } & Participant A & \multicolumn{1}{c|}{ Participant B } & Participant C & Participant D \\
\hline $\begin{array}{l}\text { Receptive language } \\
\text { abilities using } \\
\text { standardized language } \\
\text { tests (years) }\end{array}$ & 4.0 & 4.0 & 3.5 & \\
\hline \hline
\end{tabular}

Table 2. Number of correct responses for each participant on each activity

\begin{tabular}{|c|c|c|c|c|c|c|c|c|c|c|c|c|}
\hline \multirow[b]{2}{*}{ Measures } & \multicolumn{4}{|c|}{$\begin{array}{l}\text { Arts and crafts activity } \\
\text { Week } 1 \text { Participants }\end{array}$} & \multicolumn{4}{|c|}{$\begin{array}{l}\text { Food preparation activity } \\
\text { Week } 2 \text { Participants }\end{array}$} & \multicolumn{4}{|c|}{ Story time activity Week 3 Participants } \\
\hline & A & B & C & D & A & B & C & D & A & B & C & D \\
\hline Baseline 1 & 0 & 0 & 0 & 0 & 0 & 0 & 0 & 0 & 0 & 0 & 0 & 0 \\
\hline Baseline 2 & 0 & 0 & 0 & 0 & 0 & 0 & 0 & 0 & 0 & 0 & 0 & 0 \\
\hline Baseline 3 & 0 & 0 & 0 & 0 & 0 & 0 & 0 & 0 & 0 & 0 & 0 & 0 \\
\hline Week 1 day 1 & 0 & 2 & 0 & 0 & 0 & 0 & 0 & 0 & 0 & 0 & 0 & 0 \\
\hline Week 1 day 3 & 5 & 4 & 3 & 0 & 2 & 0 & 0 & 0 & 0 & 1 & 0 & 0 \\
\hline Week 1 day 5 & 8 & 6 & 8 & 3 & 1 & 1 & 1 & 1 & 0 & 2 & 0 & 0 \\
\hline Week 2 day 1 & 8 & 8 & 6 & 7 & 1 & 1 & 1 & 1 & 0 & 0 & 0 & 0 \\
\hline Week 2 day 3 & 8 & 7 & 7 & 5 & 6 & 7 & 6 & 7 & 1 & 0 & 0 & 0 \\
\hline Week 2 day 5 & 8 & 5 & 7 & 2 & 8 & 7 & 8 & 7 & 0 & 0 & 0 & 1 \\
\hline Week 3 day 1 & 8 & 7 & 7 & 6 & 8 & 7 & 8 & 6 & 0 & 0 & 0 & 0 \\
\hline Week 3 day 3 & 8 & 7 & 7 & 7 & 8 & 8 & 8 & 7 & 6 & 5 & 5 & 6 \\
\hline Week 3 day 5 & 7 & 6 & 7 & 7 & 8 & 8 & 8 & 7 & 7 & 7 & 5 & 6 \\
\hline
\end{tabular}


Table 3. The acquisition of specific target vocabulary items over the intervention period

\begin{tabular}{|c|c|c|c|c|c|c|c|c|c|c|c|}
\hline \multirow[b]{2}{*}{ No } & \multirow[b]{2}{*}{ Target } & \multirow[b]{2}{*}{ Word class } & \multicolumn{9}{|c|}{ Number of participants with the correct responses } \\
\hline & & & $\begin{array}{c}\text { Week } 1 \\
\text { Day } 1\end{array}$ & $\begin{array}{l}\text { Week } 1 \\
\text { Day } 3\end{array}$ & $\begin{array}{c}\text { Week } 1 \\
\text { Day } 5\end{array}$ & $\begin{array}{c}\text { Week } 2 \\
\text { Day } 1\end{array}$ & $\begin{array}{c}\text { Week } 2 \\
\text { Day } 3\end{array}$ & $\begin{array}{c}\text { Week } 2 \\
\text { Day } 5\end{array}$ & $\begin{array}{l}\text { Week } 3 \\
\text { Day } 1\end{array}$ & $\begin{array}{c}\text { Week } 3 \\
\text { Day } 3\end{array}$ & $\begin{array}{c}\text { Week } 3 \\
\text { Day } 5\end{array}$ \\
\hline 1 & Sheep & Noun & 1 & 3 & 4 & 4 & 4 & 4 & 4 & 4 & 4 \\
\hline 2 & Cotton wool & Noun & 0 & 1 & 3 & 4 & 4 & 4 & 4 & 4 & 4 \\
\hline 3 & More & Adjective & 0 & 1 & 3 & 4 & 3 & 4 & 4 & 4 & 4 \\
\hline 4 & Less & Adjective & 1 & 1 & 3 & 4 & 3 & 3 & 3 & 3 & 3 \\
\hline 5 & Decoration & Noun & 0 & 0 & 4 & 4 & 4 & 4 & 4 & 4 & 4 \\
\hline 6 & Messy & Adjective & 0 & 2 & 4 & 4 & 4 & 4 & 4 & 4 & 4 \\
\hline 7 & Same & Adjective & 0 & 1 & 2 & 3 & 3 & 2 & 3 & 4 & 3 \\
\hline 8 & Different & Adjective & 0 & 1 & 2 & 3 & 3 & 2 & 3 & 4 & 3 \\
\hline 9 & Taste & Verb & 0 & 0 & 0 & 0 & 4 & 4 & 4 & 4 & 4 \\
\hline 10 & Yummy & Adjective & 0 & 0 & 2 & 1 & 4 & 4 & 4 & 4 & 4 \\
\hline 11 & Strawberry & Noun & 0 & 1 & 0 & 0 & 3 & 4 & 3 & 3 & 4 \\
\hline 12 & Empty & Adjective & 0 & 1 & 0 & 1 & 2 & 3 & 3 & 3 & 3 \\
\hline 13 & Full & Adjective & 0 & 0 & 0 & 0 & 3 & 4 & 4 & 4 & 4 \\
\hline 14 & Big & Adjective & 0 & 0 & 0 & 0 & 4 & 4 & 4 & 4 & 4 \\
\hline 15 & Small & Adjective & 0 & 0 & 2 & 1 & 4 & 4 & 3 & 4 & 4 \\
\hline 16 & Pink & Adjective & 0 & 0 & 0 & 0 & 3 & 1 & 2 & 3 & 3 \\
\hline 17 & High & Adjective & 0 & 0 & 0 & 0 & 1 & 0 & 0 & 4 & 4 \\
\hline 18 & Low & Adjective & 0 & 0 & 0 & 0 & 0 & 0 & 0 & 4 & 4 \\
\hline 19 & Soft & Adjective & 0 & 0 & 0 & 0 & 0 & 0 & 0 & 2 & 3 \\
\hline 20 & Hard & Adjective & 0 & 0 & 0 & 0 & 0 & 0 & 0 & 1 & 0 \\
\hline 21 & Three & Adjective & 0 & 0 & 0 & 0 & 0 & 0 & 0 & 4 & 2 \\
\hline 22 & Hot & Adjective & 0 & 0 & 0 & 0 & 0 & 0 & 0 & 3 & 4 \\
\hline 23 & Cold & Adjective & 0 & 0 & 0 & 0 & 0 & 0 & 0 & 4 & 4 \\
\hline
\end{tabular}




\begin{tabular}{|c|c|c|c|c|c|c|c|c|c|c|c|}
\hline \multirow[b]{2}{*}{ No } & \multirow[b]{2}{*}{ Target } & \multirow[b]{2}{*}{ Word class } & \multicolumn{9}{|c|}{ Number of participants with the correct responses } \\
\hline & & & $\begin{array}{c}\text { Week } 1 \\
\text { Day } 1\end{array}$ & $\begin{array}{c}\text { Week } 1 \\
\text { Day } 3\end{array}$ & $\begin{array}{l}\text { Week } 1 \\
\text { Day } 5\end{array}$ & $\begin{array}{c}\text { Week } 2 \\
\text { Day } 1\end{array}$ & $\begin{array}{c}\text { Week } 2 \\
\text { Day } 3\end{array}$ & $\begin{array}{c}\text { Week } 2 \\
\text { Day } 5\end{array}$ & $\begin{array}{c}\text { Week } 3 \\
\text { Day } 1\end{array}$ & $\begin{array}{c}\text { Week } 3 \\
\text { Day } 3\end{array}$ & $\begin{array}{c}\text { Week } 3 \\
\text { Day } 5\end{array}$ \\
\hline 24 & Broken & Adverb & 0 & 0 & 0 & 0 & 0 & 0 & 1 & 2 & 4 \\
\hline
\end{tabular}

